\title{
The Relevance of Computing Research History - The Monads-PC: A Case Study
}

\author{
A. Barbara Ainsworth, C. Avram, and J. Sheard \\ Monash University, Melbourne, Australia \\ museum@infotech.monash.edu.au
}

\begin{abstract}
This chapter tells of the Monash Museum of Computing History, how it was started in 2001 and its purpose to preserve the computing history of Monash University and present this history to members of the University and the general public. It also describes Monash University's: MONADS research project.
\end{abstract}

Keywords: Monads, Monads-PC, Monash Museum of Computing History.

\section{Introduction}

The Monash Museum of Computing History (MMoCH) was started in 2001 to preserve the computing history of Monash University and present this history to members of the University and the general public. The Museum provides material for teaching staff on campus. To meet these objectives, the museum has been collecting computing material directly relating to Monash University including original hardware and software used on campus as well as biographical material relating to staff and students participating in IT related areas of study. To help with current teaching requirements, the museum is building a small computing reference collection to demonstrate key computing technologies. The museum has a research program directed towards the provenance of artefacts in the collection and also biographical material on people related to computing developments and use at Monash University.

In 2006 the $\mathrm{MMoCH}$ opened a new permanent exhibition. In view of our teaching commitments, the display has a mixture of typological approach and thematic ideas. During the design phase of the display, the staff felt it was important to show and important for students to see a multiplicity of objects because many computers and calculators appear to have similar functions but achieve this through different architecture.

To meet the design philosophy of the museum, the display is divided into four sections.

1. The role of calculating devices in the pre-development of computers

2. The development of computers within a chronological framework of photographic images of Australian society 
3. The Ferranti Sirius computer which was the first computer installed at Monash University

4. Monash computer legends (a select rotating biographical display on people connected with Monash University and computing)

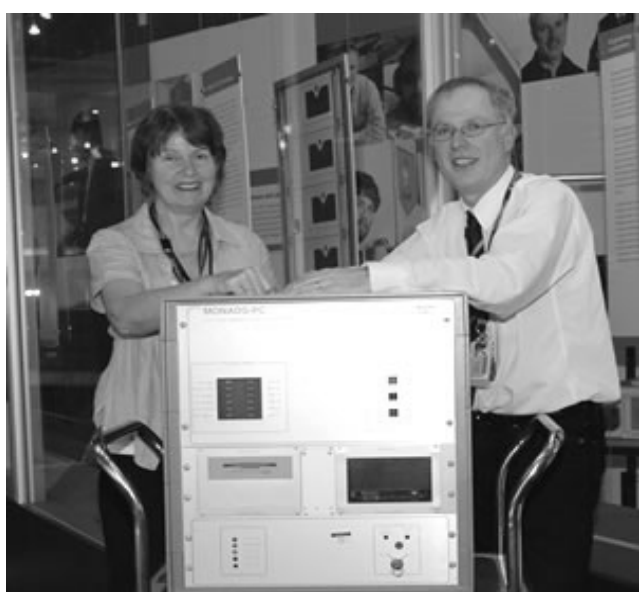

Fig. 1. MMoCH Director, Ass. Professor Judy Sheard and Professor David Abramson with the MONADS-PC in the Museum exhibition space 2008. Source: Chris Avram, MMoCH (MONADSPC, MMoCH collection item 2009.032)

As part of the Monash computer legends display, the original display was updated in 2008 with biographies on Professor David Abramson and Professor John Rosenberg who both studied and worked at Monash University during their careers. Research for this display highlighted a project, entitled the MONADS project that both professors had participated in during their studies. A custom-designed computer built during this project at Monash University, called the MONADS-PC, was located in 2008 at the University of Ulm, Germany. Through the efforts of Professor David Abramson and Jörg Siedenburg (Dipl.-Ing.), Faculty of Computer Science, Department SGI, University of Ulm, the MONADS-PC was shipped back to Australia and donated to the $\mathrm{MMoCH}$.

The donation of the MONADS PC required some months of investigation into the provenance of the computer to establish the computer's date and history and then place its significance within the development of the whole MONADS project.

This work provides an interesting case study on the relevance of researching computer history and the lessons it can provide for approaches in modern research. The Monads project was an innovative project over more than 20 years, involving cross-institutional and international collaboration. Its work developed new approaches to both hardware and software. What were the successful features of the project? How can this be applied to modern research?

\section{The Monads Project}

In 1976 several staff and students in the Department of Computer Science, Monash University started a new research project called the MONADS project. It was initiated and directed by Professor J.L. Keedy. This was the start of more than twenty years of research under this umbrella project.

The MONADS Project had a number of different phases including software and hardware research. After the project was started at Monash University, research 
continued at different institutions including the University of Newcastle and later the University of Sydney as Monash staff and researchers took up positions at other institutions and worked with a number of researchers and students. Professor Keedy worked during the 1980s and 1990s in Germany as well as in Australia and moved aspects of the MONADS Project to the Technical University of Darmstadt and later to the University of Bremen and the University of Ulm. Over the life of the project, many different people have contributed to the various aspects of the project.

Of particular interest to the MMoCH is the development of the MONADS-PC in the 1980s. The MONADS-PC is a micro-programmed workstation designed to support a very large virtual memory, capability-based addressing and information hiding software modules. The MONADS-PC was designed in the mid 1980s at Clayton campus, Monash University by Professor David Abramson and Professor John Rosenberg. A number of MONADS-PC models were constructed at Monash University and the University of Newcastle during the 1980s. The computer donated to the MMoCH was sent to Germany from Australia in 1990.

For a project overview, Professor Keedy has created a detailed technical discussion of the project at http://www.monads-security.org/ with an interesting list of publications and thesis work associated with the project at different phases.

\section{Background to Computer Research at Monash University and Start of MONADS Project}

Monash University was established in 1958 and its first computer was installed in 1962. The Monash Computer Centre operated the computing equipment and also undertook some teaching. The University later developed an academic department in the Faculty of Science for teaching computer science at the Clayton campus during the 1960s. Professor Chris Wallace was appointed as Chair of Information Science in December 1967. The first subject was Information Science 303 for third year students. Seven honours students were enrolled in 1970. This was the beginning of a computer science research program. During 1972 the Department purchased its own HP2100A computer which was later modified for various research projects. In 1975 the Department's name was changed to Computer Science. This department grew to have a complete subject range through all levels of students and established a world-recognised research program. In 1990 the University created the Faculty of Computing and Information Technology which is now the Faculty of Information Technology ${ }^{1}$.

It was during the developmental stage of teaching and research at Monash University that Dr. J.L. (Les) Keedy moved from England to become a Lecturer in the Department in 1974. He had previously worked with ICL (International Computers Ltd) in England ${ }^{2}$. In 1976 Keedy created the MONADS Project drawing on his experiences at ICL.

1 Rood, S. (2008). From Ferranti to Faculty: Information Technology at Monash University, 1960 to 1990. Monash University ePress, Melbourne. Australia.

2 J.L. Keedy biography http: / / www . jlkeedy. net/biography . html Accessed January 17, 2011. 
Professor Keedy, in his notes regarding the development of the project, defines the original aims of the project as:

- "To develop practical software engineering techniques for improving the specification, design, implementation and maintenance of large software systems, i.e. systems involving tens, hundreds and even thousands of man years of effort.

- To develop practical techniques for guaranteeing the security (i.e. the confidentiality, integrity and availability) of information held in large computer systems." 3

The name MONADS was taken from a word created by the philosopher Leibniz. Leibniz used the word to describe the basic elements that the world is constructed from. It was Leibniz's belief that these elements were unable to interact with each other but worked together in perfect harmony (in his view because they each had a spark of the deity!) ${ }^{4}$. The Monads program adopted this principal for software systems (but without a spark of the deity as John Rosenberg remarked ${ }^{5}$ ). As Keedy states,

"We believe that systems should be composed of stable and relatively independent components which have minimal interactions with each other. This can be achieved in practice by rigorously applying the informationhiding principle." 6

The project was also focused on the security of the information held in a computer and this developed into work on producing hardware that would support a capabilitybased addressing system. Capability-based addressing is a method for a computer to have controlled access to 'capabilities'. The computer stores information in the memory but with capability addressing, these are protected objects and access to them is controlled by the kernel. This effectively allows for selective access to the memory by different users depending upon the software parameters.

In the project, the team developed hardware, languages, operating systems and software engineering techniques to meet its objectives. As such, it brought together specialists able to contribute to all of these areas.

In their 1985 article, Rosenberg and Abramson caution that the project appears to have a strong emphasis on hardware, computer architecture and operating systems as the main objectives. However they state,

3 See Keedy, J.L. The Monads Project http: / / www . monads-security . org/

Accessed January 17, 2011.

4 Monash Review (1986) "New Computer Helps Wipe Out Bugs" No. 1 - 86 p.1-2,

http: / / www.adm.monash.edu.au/records_archives/assets /

docs / pdf/monash-review/1986- .pdf Accessed January 17, 2011.

5 Rosenberg, John in email to Dr Judy Sheard commenting on Monads draft paper November 17, 2012.

6 Keedy, J.L., Abramson, D., Rosenberg, J \& Rowe, D.M. (1982) “The MONADS Project Stage 2: hardware Designed to Support Software Engineering techniques", Proc. $9^{\text {th }}$ Australian Computer Conference, Hobart, August 1982, pp.575-580 p.576. 
"The central theme of the project has always been and still is investigation of software engineering techniques for development of large 'real world' applications.",

The different phases of the project were given sub-names with MONADS as the common feature. The project can be divided into: Monads I, Monads II, Monads II/2, Monads III, MONADS-PC, Distributed MONADS-PC, Monads MM.

There was also considerable work made in the area of languages including: Leibniz, L1.

Later projects that have succeeded the MONADS Project include the SPEEDOS Project which was initiated by Prof. Keedy and his research group in 1998 at the University of Ulm, Germany. Another project called S-RISC was commenced after $1993^{8}$.

\section{MONADS Project Stages}

\subsection{MONADS I}

The project commenced with the first stage that became known as MONADS I. Work was started by three Monash University $\mathrm{PhD}$ students - John Rosenberg, Ramamohanarao (Rao) Kotagiri and Ian Richards under the supervision of Professor J.L. Keedy. The Monads project team worked on both software and hardware developments to meet the needs of the project. The department's HP2100A minicomputer was modified to suit their requirements. It had already been modified by a postgraduate student, Rob Hagan, under the supervision of Professor Chris Wallace, in 1975 for their work on virtual memory. By 1976 the HP2100A memory hardware had been modified to support a demand-paged virtual memory. More adjustments were made in 1977 and laid the foundation for the hardware for the MONADS project ${ }^{9}$.

John Rosenberg started work on creating the MONADS hardware kernel to be installed on the HP2100A. This Hardware Kernel was applied to four major areas: Memory Management, Process Management, I/O Management and Protection. This work was in part funded by a grant from the Australian Research Grants Committee (number F77/15337 I) and a Monash University Postgraduate Scholarship ${ }^{10}$. It is significant that this ARGC grant was probably the first one awarded by this Committee in the field of computer science research ${ }^{11}$. The MONADS I used the

7 Rosenberg, J. and Abramson, D.A. "The MONADS Architecture: Motivation and Implementation", Proceedings of First Pan Pacific Computer Conference, Melbourne, 1985, pp. 410-423. Invited Paper. p.411, http: / /messagelab.monash.edu . au/

Publications / Publication?action=download\&upname= monadsarch_motimp.pdf Accessed September 14, 2012.

8 See http: //www. monads-security.org

9 Keedy, J.., Wallace, C.S., Rosenberg, J., Ramamohanarao, K., Richards, I., and Georgiades, A. (1978) A Collection of Papers on the Monads Operating System. Monads Report No. 1, Monash University - Department of Computer Science, February 1978: p.3-4.

10 Keedy, J.., Wallace, C.S., Rosenberg, J., Ramamohanarao, K., Richards, I., and Georgiades, A. (1978) P.25-26.

11 Email from Prof. J.L. Keedy to Ass. Prof Judy Sheard 14 November 2012. 
modified hardware and the new software in a pilot version by 1978 . However it did not meet the requirements of the project. To undertake the principle of informationhiding, the team worked on a software system that broke up information into small information hiding modules, these then performed specific tasks. At this stage of the project, the MONADS I hardware did not work effectively with the software modules and was inefficient ${ }^{12}$.

Rosenberg, Kotagiri and Richards all completed their PhD thesis work on elements of the MONADS Project. John Rosenberg submitted in 1979, Rao Kotagiri completed his thesis in 1980 while Ian Richards finished in $1981^{13}$.

\subsection{MONADS II and II/2}

Work commenced in 1980 on a new stage, a report in 1982 acknowledged the team working on the project. They were listed as: J.L. Keedy, J. Rosenberg, D. Abramson, David Rowe, Peter Dawson, Mark Evered, Mark Halpern, Ed Gehringer, Glenda Patterson, Kotagiri Ramamohanarao, Ian Richards, John Thomson, Brian Wallis, John Wells ${ }^{14}$. This group represented a mixture of $\mathrm{PhD}$ students and Honours students as well as staff.

In 1980 David Abramson, then a PhD student at Monash University, started work on MONADS II with funding from the Australian Research Grants Committee (ARGC Grant F80/15191), the Australian Computer Research Board and the Monash Special Research Fund (Grant no. SC18/79). This stage of the project also used the modified HP2100A computer. The processor in this model could develop 31-bit virtual addresses which were converted into physical memory addresses by the virtual memory manager. It had $400 \mathrm{~Kb}$ of physical memory. The system also used $2 \times 5 \mathrm{Mb}$ disk drives, 1 x $80 \mathrm{Mb}$ Winchester disk and a terminal multiplexor. The processor could also communicate with another unmodified HP2100A and a VAX 11/780 computer which they were using at the time for program compilation ${ }^{15}$. Abramson in his 1983 paper described the new hardware component of the project for the MONADS II as complete but noted several problems and described a new system called MONADS II/2. There was a move away from the HP2100A to using a Z8000 micro-computer with two Intel Multibuses. MONADS II/2 proposed a larger addressing range moving from 31-bit to 47-bit and a larger physical memory ${ }^{16}$. At this time, Professor J.L. Keedy completed his unsupervised staff $\mathrm{PhD}$ thesis in 1982, focusing on software engineering in the MONADS computer architecture ${ }^{17}$.

12 Abramson, D.A. 1983 “The MONADS II Computer System," Proc. $6^{\text {th }}$ Australian Sciences Conference, Sydney, February 1983, pp1-10. p.2.

13 Keedy, J.L. The Monads Project. p.8 list of PhD Theses, http: / / www. monads-security.org/ Accessed January 17, 2011.

14 Keedy, J.L. (1978) The MONADS Operating System p.5 in Keedy et al. (1978) A Collection of Papers on the MONADS Operating System. MONADS Report No.1 Monash University. - Department of Computer Science, February 1978.

15 Abramson 1983 p.3.

16 Abramson 1983 p.7.

17 Keedy, J.L. The Monads Project. p.8 list of PhD Theses, http: / / www. monads-security.org/ Accessed January 17, 2011. 


\subsection{MONADS III}

The project continued to evolve and work started on MONADS III. However it was not completed due to the resignation of two main researchers from Monash University - Professor Keedy and Dr (later Professor) Rosenberg. Professor Keedy was appointed to the Chair in Operating Systems at the Technical University of Darmstadt in Germany in $1982^{18}$. He did not have the facilities to work on hardware developments but concentrated on software components of the project from 1982 to 1985. Dr Rosenberg also resigned from the project in 1982 and he left Monash University for two years, returning in $1984^{19}$. Work continued at Monash University on a scaled down version of MONADS III, called the MONADS II/2.

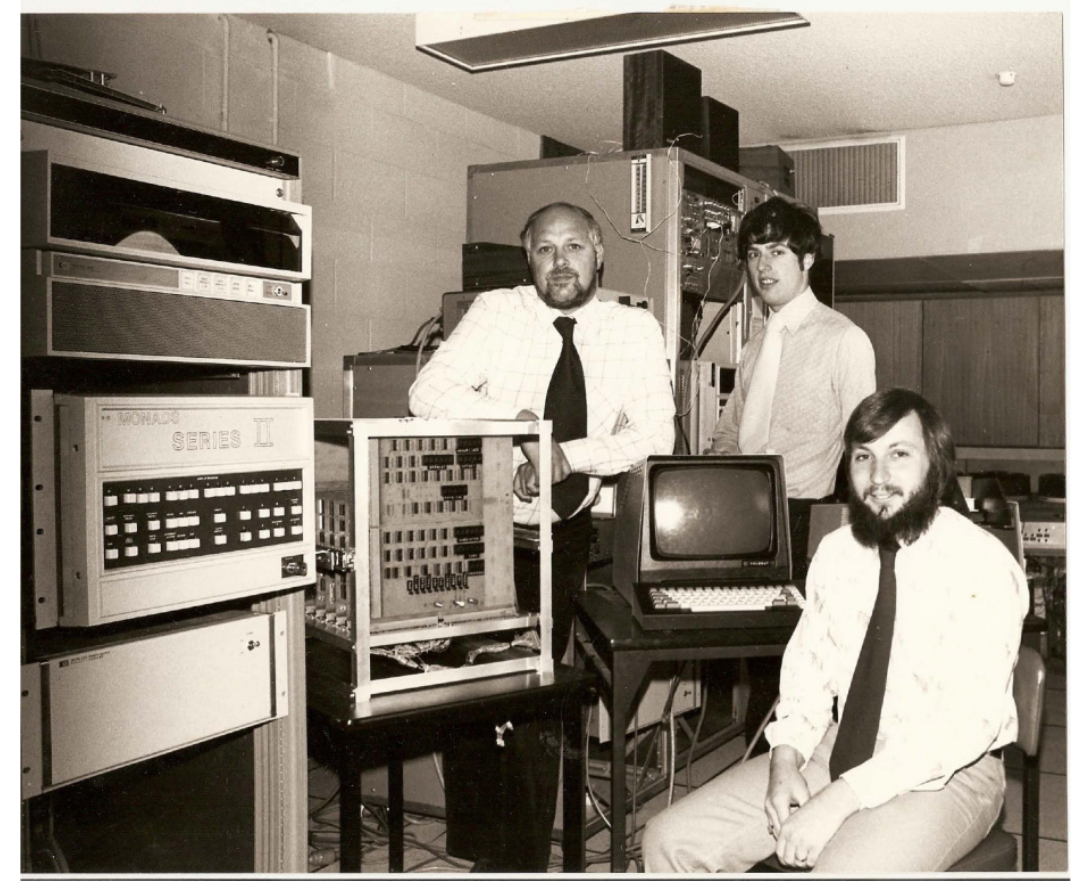

Fig. 2. Professor Les Keedy, Professor David Abramson and Professor John Rosenberg photographed in 1982 with the HP2100A and MONADS Series II hardware, Monash University. Source: David Abramson

18 Keedy, J.L. The Monads Project p.2, http: / / www .monads-security.org/ Accessed January 17, 2011.

19 Rosenberg J and Abramson D.A. (1985) "MONADS-PC - A Capability-Based Workstation to Support Software Engineering", Proceedings of Eighteenth Annual Hawaii International Conference on System Sciences, January 2-4, 1985 pp.222-230. p.230,

http: / / messagelab. monash. edu. au/Publications / Publication?acti on=download\&upname=monads_sesupport .pdf Accessed September 14, 2012. 
Ed Gehringer, visiting Monash University as a Fulbright Fellow under the Australian-American Education Foundation from May 1981- January 1982 from Carnegie Mellon University, undertook to write a description of MONADS III system architecture. This became MONADS Report No. $12^{20}$.

\subsection{MONADS-PC}

Professor John Rosenberg and Professor David Abramson started work on the MONADS-PC in 1984 at Monash University. They designed and built the first MONADS-PC, a single board computer. The MONADS-PC computer had 60-bit virtual addresses with capability registers and an efficient address translation unit. The project was a combination of hardware and software research to implement a paged virtual memory which was accessed by large addresses. There were several examples of the MONADS-PC built. The MONADS project continued using this hardware.

The MONADS-PC was designed to meet the need to limit the number of errors that occur when multiple programs interact within the computer and access the same data. Data can be stored permanently in the computer on the disc or temporarily in the memory while the computer is in active use. To meet the hardware requirements for this process, the hardware had to be modified and several new elements were added to allow the computer to map where all the addresses were located at the same time. The MONADS-PC was one of the first systems to place all storage in a single, distributed, virtual address space. The different programs and their specific use of the data are isolated into modules and they are controlled by software that only allows interaction by certain users. No module can change data in another module, so if an error occurs in one module, the error is not copied into another module. The MONADS-PC was a multi-user system and could support 5 or 6 terminals at the same time.

The project also developed a new computer language called Leibniz to provide the instructions for the control of the modules. This work was designed by Mark Evered who commenced at Monash University but transferred to Darmstadt under the supervision of Professor Keedy. He was awarded his PhD entitled "Leibniz A Language to Support Software engineering" in 1985 from the Technical University of Darmstadt.

David Abramson developed the circuit board for the first MONADS-PC. The prototype is currently on loan to $\mathrm{MMoCH}$ and on display in the Legends display section which features a brief biography on both Professor Abramson and Professor Rosenberg. The board has an unusual circuit-board construction method which employs insulated wires embedded in epoxy-resin that allowed very high-density circuit board layouts. Apart from the custom-designed board, the MONADS-PC was constructed from commercially available components ${ }^{21}$.

20 Gehringer, Edward F. (1982) MONADS: A Computer Architecture to Support Software Engineering. MONADS Report No. 12. Monash University - Department of Computer Science.

21 The Age (1985) "International spotlight on Monash pair", The Age, Tuesday, February 5, 1985 p.30, Melbourne. 
Work by Abramson and Rosenberg in the mid-1980s was largely carried out using resources from within Monash University's Department of Computer Science. In 1986 the project obtained funding from the Australian Research Grants Scheme as well as a collaborative research grant with the CSIRO Division of Information Technology ${ }^{22}$.

Dr Rosenberg and Dr Abramson submitted a paper to the $18^{\text {th }}$ Hawaii International Conference on System Sciences in 1985 on the MONADS-PC research. The paper was entitled "MONADS-PC - A Capability-Based Workstation to Support Software Engineering" and received the Best Paper Award in the Hardware Track. It was the only Australian paper presented at the conference ${ }^{23}$.

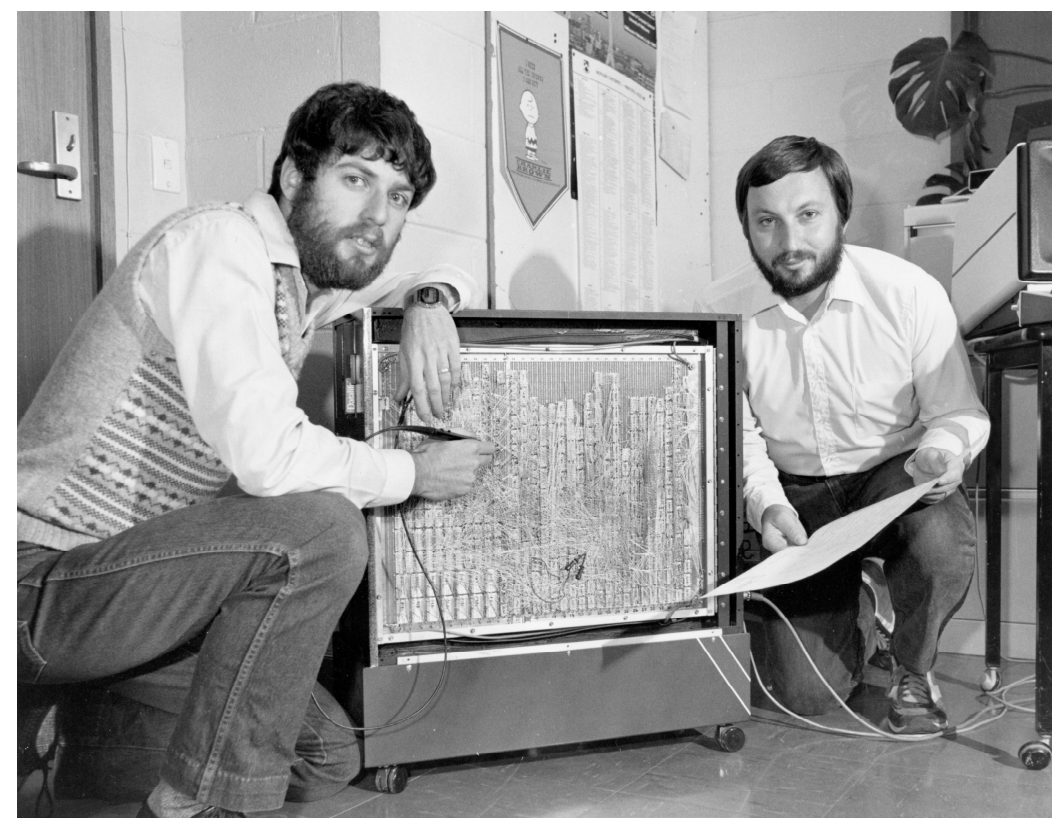

Fig. 3. Photograph of Professor David Abramson and Professor John Rosenberg in 1985 with a version of the MONADS-PC, Monash University. Source: Monash University Archives MONPIX IN633.

There was some suggestion that the research could have some commercial future. Professor Rosenberg mentioned this idea in a 1985 article in The Age newspaper but cautioned that it would take two or three years to become a commercially viable product $^{24}$. Commercial production of the MONADS-PC did not eventuate.

22 Monash Review (1986) "New Computer Helps Wipe Out Bugs" No. 1 - 86 p.1-2; http: / /www.adm.monash.edu.au/records_archives/assets/docs / pdf/monash-review/1986-.pdf Accessed January 17, 2011.

23 Williams, P. (1985) “Australian hardware impresses Hawaiian conference", Computer Weekly, January 25, 1985.

24 The Age (1985) "International spotlight on Monash pair", The Age, Tuesday, February 5, 1985 p.30, Melbourne. 
Professor Keedy installed a MONADS-PC at the University of Bremen after he took up his position there in 1988 and then transferred it to the University of Ulm in 1993. This model of the MONADS-PC was built by David Koch at the University of Newcastle, New South Wales specifically for Professor Keedy using a custom circuit board. Some other units were partially built at the University of Sydney by David Koch while he was seconded to Sydney about 1991. Although these were not completed, the extra units (possibly one or two) and other custom circuits were sent to Germany as well ${ }^{25}$. David Koch's completed MONADS-PC was sent to Germany in 1990. Professor Rosenberg travelled to Germany and helped to install the computer with local research staff. This example of the MONADS-PC was donated back later to the Monash Museum of Computing History in 2008. Another MONADS-PC was built by Jörg Siedenburg at the University of Ulm ${ }^{26}$.

\subsection{Distributed MONADS-PC and MONADS MM}

The MONADS Project was moved to the University of Newcastle, New South Wales in 1985. Professor Keedy had returned from Germany to establish the Department of Computer Science at the University of Newcastle ${ }^{27}$. He was later joined by John Rosenberg who moved to Newcastle as Senior Lecturer. They continued to work on the project and worked with research student Frans Henskens and also David Koch.

The MONADS-PC hardware could be connected to other computers and work on the system started to look at Local Area Networks. In 1985 David Abramson and Les Keedy published an early paper world-wide on distributed shared memory, which triggered further work at the University of Newcastle on local area networks. Much of the research on kernel software design and implementation was undertaken by Frans Henskens $^{28}$.

It was also proposed to develop a new computer, MONADS-MM, which would have 128-bit virtual addresses and a massive physical memory. Research continued in Germany when Professor Keedy moved to the University of Bremen and collaboration continued with Australian based members of the project. John Rosenberg moved to Sydney University to take up the position of Professor of Computer Science in 1988 but he maintained an interest in the MONADS Project. Work also continued at the University of Newcastle and research papers were published on aspects of the Project from the different institutions. Professor Keedy later undertook work at the University of Ulm in Germany as Director of the Department of Computer Structures. The 1995 website description of the Department of Computer Structures, University of Ulm notes that the department was begun in 1993 and its initial research focus was developed from the work of Professor Keedy

25 Email from David Koch to Barbara Ainsworth December 17, 2012.

26 Email from Professor Keedy to Ass. Prof Judy Sheard November 14, 2012.

27 Keedy, J.L. Dr. (2011) The Monads Project, p.2.

http: / /www. monads-security . org Accessed December 24, 2011.

28 Keedy, J.L. Dr. (2011) The Monads Project. p.6.

http: / /www . monads-security . org Accessed December 24, 2011. 
and his assistants at the University of Bremen ${ }^{29}$. The MONADS Project was a key feature of their research programs. Work at Ulm has grown in new directions and they created a new project entitled SPEEDOS again focusing on security. Although now retired, Professor Keedy still maintains his research interest in SPEEDOS.

\section{Summary}

The MONADS project was a collaborative effort that spanned several academic institutions and combined the skills of both hardware and software specialists. The concepts developed by the team opened up development of hardware with new work in early networking, expanding hardware from 32-bit to 64-bit and major work on security software with information hiding, distributed virtual memory and capability addressing.

This research project represented the collaboration of computer departments from three Australian universities as well as three universities in Germany and a visiting scholar from the United States. Many of the key participants have continued to work in computer science research as well as take on academic roles. When Professor Keedy proposed the project in 1976, Monash University had only recently started to look at the possibilities of computer science research. It is an acknowledgment of Professor Keedy's perception of the possibilities of this research area in software engineering that the MONADS project continued for over twenty years and encouraged young computer scientists to undertake research.

Monash University played a key part in this significant research project providing both support through funding as well as encouraging research staff and students to participate as part of their academic development. The project led to new levels of research in computer science with researchers undertaking major developments in both the hardware and software components. The University encouraged this work and showed a continuous commitment to the concept of research from the beginning of the project.

The MONADS project had a long lasting influence on many of the researchers and many continued to work in the field of computer science with senior careers in academia. The project took on the name MONADS to define their approach to software being made of separate entities that work in harmony but do not interact. The actual process of the project itself proved to be the opposite of this concept with the concurrent work by different researchers in hardware and software continually interacting to create a functioning computer in the MONADS-PC.

The historical study of this project has provided a number of valuable insights into the role of different features contributing towards a successful computer project and the relevance of these insights for the modern researcher. It highlights several factors for a successful project.

29 University of Ulm, Germany- Department of Computer Structures http: / / www . uni-ulm.de/uni/vereoff/fb/93-95/133.html.en Accessed March 1, 2012. 
1. The selection and definition of the scope of a new project, its relevance to computer development

2. The selection of personnel to undertake research and their long term commitment to developing new ideas and implementing them

3. The value of collaboration between different researchers; in this case, not just one field of computer study but also across several institutions

4. The support of the parent institution for the value of long term research as well as government financial support thought specific grants

For the Monash Museum of Computing History, this study was initiated by the acknowledgment of two successful Monash University graduates in the field of computing in our biographical display area. The subsequent donation of the MONADS-PC led to a greater understanding of the role of computer research both at Monash University and at other institutions. This historical study of a computer project has much wider implications and is relevant to our approach to modern computer research.

Acknowledgements. This research project was conducted at the Monash Museum of Computing History, Monash University, Australia. $\mathrm{MMoCH}$ would like to acknowledge the contributions of Professor David Abramson, Professor J.L. Keedy and Professor John Rosenberg for their time and valuable comments on the Museum's research for provenance details on the MONADS project and the MONADS-PC in the $\mathrm{MMoCH}$ collection.

\section{References}

Abramson, D.: The MONADS II Computer System. In: Proceedings of the 6th Australian Sciences Conference, Sydney, pp. 1-10 (February 1983)

Abramson, D., Rosenberg, J., Rowe, D.M.: The MONADS Project Stage 2: Hardware Designed to Support Software Engineering Techniques. In: Proceedings 9th Australian Computer Conference, Hobart, pp. 575-580 (August 1982)

The Age, "International spotlight on Monash pair", The Age, Melbourne, p. 30 (February 5, 1985)

Computer History Museum, Online exhibition "Computer History Timeline" (2012), http: / / www. computerhistory.org/timeline/?year=1981 (accessed September 9, 2012)

Gehringer, E.F.: MONADS: A Computer Architecture to Support Software Engineering. MONADS Report No. 12. Monash University - Department of Computer Science (1982)

Keedy, J.L.: The MONADS Operating System in Keedy et al. A Collection of Papers on the MONADS Operating System. MONADS Report No.1 Monash University. Department of Computer Science (February 1978)

Keedy, J.L.: Biography of Professor Keedy (1974-2011)JLKeedy.net: http: / /www.jlkeedy. net/biography . html (accessed January 17, 2011)

Keedy, J.L.: Department of Computer Structures. University of Ulm (1995), http: / /www .uni-ulm.de/uni/veroeff/fb/93-95/133.html.en (accessed March 1, 2012) 
Keedy, J.L.: The Monads Project (2011), http://www.monads-security.org (accessed December 24, 2011)

Keedy, J., Wallace, C.S., Rosenberg, J., Ramamohanarao, K., Richards, I., Georgiades, A.: A Collection of Papers on the Monads Operating System. Monads Report No. 1, Monash University - Department of Computer Science (February 1978)

Keedy, J.L., Abramson, D., Rosenberg, J., Rowe, D.M.: The MONADS Project Stage 2: Hardware design to support software engineering techniques. In: Proceedings of Ninth Australian Computer Conference 1982, pp. 575-580 (1982)

Message Lab. Message Lab, Monash eScience and Grid Engineering Laboratory (December 22, 2008) (2012), http://messagelabe.monash.edu.au/News / MonadsandMuseum (accessed July 12, 2012)

Monash Review, New Computer Helps Wipe Out Bugs, No. 1-86, pp. 1-2 (1986), http://www.adm.monash.edu.au/records_archives/assets/docs/pdf /monash-review/1986-.pdf (accessed January 17, 2011)

Rood, S.: From Ferranti to Faculty: Information Technology at Monash University, 1960 to 1990. Monash University ePress, Melbourne (2008)

Rosenberg, J., Abramson, D.A.: The MONADS Architecture: Motivation and Implementation. In: Proceedings of First Pan Pacific Computer Conference, Melbourne (1985), http://messagelab.monash. edu.au/Publications / Publication?acti on=download (accessed September 14, 2012)

Rosenberg, J., Abramson, D.A.: MONADS-PC - A Capability-Based Workstation to Support Software Engineering. In: Proceedings of Eighteenth Annual Hawaii International Conference on System Sciences, January 2-4 (1985)

http: //messagelab. monash. edu.au/Publications/Publication?action= download\&upname=monads_sesupport . pdf (accessed September 14, 2012)

Rosenberg, J., Keedy, J.L., Abramson, D.A.: Addressing Mechanisms for Large Virtual memories. The Computer Journal 35(4), 369-375 (1992),

http: / / comjnl. oxfordjournals .org/content/35/4/369. full.pdf+html (accessed August 24, 2012)

Williams, P.: Australian hardware impresses Hawaiian conference, Computer Weekly (January $25,1985)$ 